\title{
Obituary: Dr. John Redfern
}

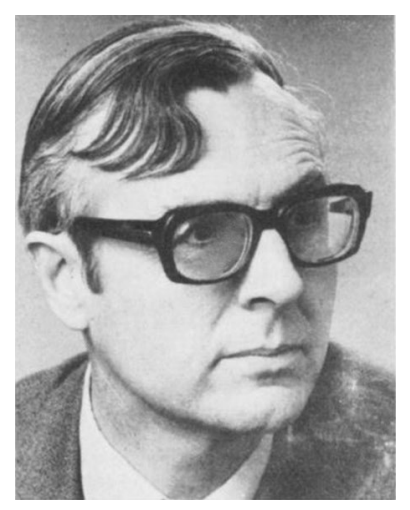

We are very sorry to inform you that Dr. John Redfern, one of the founders of ICTAC and former Managing Director of Stanton Redcroft Ltd, has passed away aged 86 years.

Together with Dr. Robert Mackenzie, John initiated the organisation of the First International Conference on Thermal Analysis in Aberdeen in 1965. The considerable success of the Conference resulted in the Second International Conference being held in Worcester, Mass, USA, in 1968. At this meeting, the International Confederation for Thermal Analysis (which later became ICTAC) formally came into being, with John as Secretary and Chairman of the Publications Committee.

He was equally pioneering at a national level and in 1964, while a chemistry lecturer at Battersea College of Technology (now the University of Surrey), he organised a very successful thermal analysis conference. This led directly to the formation of the UK Thermal Methods Group and John followed on from Robert Mackenzie to become its second
Chairman in 1967. While at Battersea College, John together with his research student Tony Coats also developed the well-known kinetic method that bears their names.

John also was the founder of the Journal of Thermal Analysis and Calorimetry in 1969, the first international journal in the field of thermal analysis and calorimetry. He made considerable and unforgettable efforts to the success of the journal.

Although suffering from poor health for several years, following a stroke, he made a considerable effort to be at the 50th Anniversary Meeting of the Thermal Methods Group in Cambridge in 2015. This was greatly appreciated by his many colleagues and friends and by the younger members who had the opportunity of meeting a founder of the Group.

In 2018, the Thermal Methods Group established the Mackenzie-Redfern Bursaries in memory of Dr Robert Mackenzie and Dr John Redfern, the Group's founders. The aim of the Bursaries is to help early career scientists present a paper or poster at a Thermal Methods Group TAC National Conference.

We send our deepest sympathy to his family.

Wim de Klerk President ICTAC

Ted Charsley

(Past President ICTAC, Past Chairman TMG)

Publisher's Note Springer Nature remains neutral with regard to jurisdictional claims in published maps and institutional affiliations. 